\title{
Correction to: Evaluating Corrosion Resistance of Biomedical Ti-6AI-4V Alloys Fabricated via Additive Manufacturing Using Electrochemical Critical Localized Corrosion Potential
}

\author{
Jae-Bong Lee ${ }^{1}\left[\right.$ (D) Dong-II Seo ${ }^{1} \cdot$ Hyeon-Yeong Chang ${ }^{2}$
}

Published online: 23 July 2021

(c) The Korean Institute of Metals and Materials 2021

\section{Correction to: \\ Metals and Materials International (2021) 27:2353-2359 https://doi.org/10.1007/s12540-021-00972-1}

In the original publication, the abstract was missing from this article and the abstract section is given in this correction.

\begin{abstract}
Titanium (Ti) and its alloys have attractive properties like high strength-to-weight ratio, excellent formability, biocompatibility, and corrosion resistance. These alloys are conventionally produced via subtractive manufacturing (SM) method, but recently new additive manufacturing (AM) method has been developed and can fabricate desired products by melting and stacking powders using a laser, electron beam, or a plasma arc. From a mechanical perspective, the strength and ductility of AM Ti alloys are comparable to or above those fabricated via SM because of their unique microstructure. However, AM Ti alloys corrosion resistance is still unknown, because of their defects and formation of martensite phase resulting from rapid solidification, hence new strategies were developed to evaluate localized corrosion resistance Consequently, a measurement method based on electrochemical critical localized corrosion temperature (E-CLCT) was adopted as ISO 22910:2020 but its application should be limited at normal ranges of $\mathrm{pH}$ and temperatures corresponding to the human body because of the temperature scan during the E-CLCT testing. Therefore,
\end{abstract}

The original article can be found online at https://doi.org/10.1007/ s12540-021-00972-1.

Jae-Bong Lee

leejb@kookmin.ac.kr

1 School of Advanced Materials Engineering, Kookmin University, Seoul 02707, Republic of Korea

2 Korea Electric Power Corporation Engineering \& Construction (KEPCO E\&C), Technology \& Strategy Research Institute, Gimcheon 39660, Republic of Korea electrochemical critical localized corrosion potential (E-CLCP) was introduced and proposed in this paper as a new criterion in evaluating the resistance against localized corrosions in biomedical AM Ti alloys in human body environments. AM Ti alloy samples without a hole and crevice former as well as an electrochemical polarization cell were used in the artificial physiological fluids. This study explores how to efficiently evaluate the localized corrosion resistance of AM Ti alloys such as Ti-6Al-4V by measuring E-CLCP values in the artificial physiological fluids.

The original article has been corrected.

Publisher's Note Springer Nature remains neutral with regard to jurisdictional claims in published maps and institutional affiliations. 